Canadian

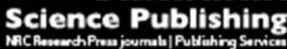

Applied Physiology, Nutrition, and Metabolism Physiologie appliquée, nutrition et métabolisme

\title{
LACTATE MINIMUM UNDERESTIMATES THE MAXIMAL LACTATE STEADY STATE IN SWIMMING MICE
}

\begin{tabular}{|r|l|}
\hline Journal: & Applied Physiology, Nutrition, and Metabolism \\
\hline Manuscript ID & apnm-2016-0198.R2 \\
\hline Manuscript Type: & Article \\
\hline Date Submitted by the Author: & 04-Aug-2016 \\
\hline Complete List of Authors: & $\begin{array}{l}\text { Rodrigues, Natalia; University of Campinas, School of Applied Sciences } \\
\text { Torsoni, Adriana; University of Campinas, School of Applied Sciences } \\
\text { Fante, Thais; University of Campinas, School of Applied Sciences } \\
\text { dos Reis, Ivan; University of Campinas, School of Applied Sciences } \\
\text { Gobatto, Claudio; University of Campinas, School of Applied Sciences } \\
\text { Manchado-Gobatto, Fúlvia; University of Campinas, School of Applied } \\
\text { Sciences }\end{array}$ \\
\hline Keyword: & $\begin{array}{l}\text { Blood lactate, Maximal lactate steady state, Anaerobic threshold, Aerobic } \\
\text { capacity }\end{array}$ \\
\hline &
\end{tabular}




\title{
LACTATE MINIMUM UNDERESTIMATES THE MAXIMAL LACTATE STEADY STATE IN
} SWIMMING MICE

\author{
AUTHORS \\ Natalia Almeida Rodrigues ${ }^{1 \mathrm{a}}$, Adriana Souza Torsoni ${ }^{2 \mathrm{e}}$, Thais Fante ${ }^{2 \mathrm{f}}$, Ivan Gustavo Masselli dos Reis ${ }^{1 \mathrm{~b}}$, \\ Claudio Alexandre Gobatto ${ }^{1 c}$, Fúlvia Barros Manchado-Gobatto ${ }^{1 \mathrm{~d}}$ \\ ${ }^{1}$ Laboratory of Applied Sports Physiology, School of Applied Sciences, University of Campinas, Limeira, \\ São Paulo, Brazil. \\ anar.camp@gmail.com; ${ }^{b}$ ivanbarizom@hotmail.com; claudio.gobatto@fca.unicamp.br; \\ dfulvia.gobatto@fca.unicamp.br \\ ${ }^{2}$ Laboratory of Metabolic Disorders, School of Applied Sciences, University of Campinas, Limeira, São \\ Paulo, Brazil.

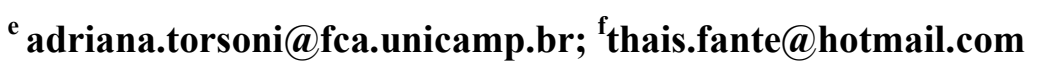

\section{CORRESPONDING AUTHOR}

Fúlvia Barros Manchado-Gobatto

+551937016669

fulvia.gobatto@fca.unicamp.br

School of Applied Sciences, University of Campinas - UNICAMP

R. Pedro Zaccaria, 1300

Caixa Postal 1068, CEP 13484-350 - Limeira - São Paulo 


\begin{abstract}
The intensity of lactate minimum (LM) has presented a good estimate of the intensity of maximal lactate steady state (MLSS); however, this relationship has not yet been verified in the mouse model. We proposed validating the LM protocol for swimming mice by investigating the relationship among intensities of LM and MLSS as well as differences between genders, in terms of aerobic capacity. Nineteen mice (male: 10, female: 9) were submitted to the evaluation protocols for LM and MLSS. The LM protocol consisted of hyperlactatemia induction (30 s exercise $(13 \% \mathrm{bm}), 30 \mathrm{~s}$ resting pause and exhaustive exercise $(13 \% \mathrm{bm}), 9 \mathrm{~min}$ resting pause and incremental test). The LM underestimated MLSS (mice: 17.6\%; male: 13.5\%; female: 21.6\%). Pearson's analysis showed a strong correlation among intensities of MLSS and LM (male $[r=0.67, p=0.033$; female $[r=$ 0.86, $\mathrm{p}=0.003]$ ), but without agreement between protocols. The Bland and Altman analysis showed that bias was higher for females $(1.5[0.98] \% \mathrm{bm}$; Mean [MLSS and LM]: 4.4-6.4\% bm) as compared to males $(0.84$ [1.24] \% bm; Mean [MLSS and LM]: 4.5-7.5\% bm). The error associated with the estimated of intensity for males was lower when compared to the range of means for MLSS and LM. Therefore, the LM test could be used to determine individual aerobic intensity for males (considering the bias) but not females. Furthermore, the females supported higher intensities than the males. The differences in body mass between genders could not explain the higher intensities supported by the females.
\end{abstract}

Keywords: blood lactate, maximal lactate steady state, anaerobic threshold, aerobic capacity 


\section{Introduction}

Physical exercise promotes many benefits for improving health and preventing chronic diseases (Schjerve et al. 2008; Fisher et al. 2015; Smith-Ryan et al. 2015), in addition to enhanced physical fitness (Little et al. 2011; Yan et al. 2012; Kang et al. 2013). Rodent models allow to investigate the exercise response associated to these benefits with controlled manipulations, minimal environmental variations and invasive analysis, in which provide depth information about cellular and molecular pathway (Levin 2008; Stanford et al. 2015; Garton et al. 2016). Furthermore, the behavior of some physiologic responses on exercise have been similar to found in humans (Wisloff et al. 2001; Kemi et al. 2002; Billat et al. 2003; Garton et al. 2016).

Evaluation protocols have been validated for rodent, mostly rats, to determine intensity of anaerobic threshold (AT) (Faude et al. 2009), in which allows the control and the prescription of intensity in acute sessions of exercise and training (de Araujo et al. 2012; de Araujo et al. 2013; Almeida et al. 2014; Petriz et al. 2015). Studies regarding evaluation protocols have reported that variations in the individual intensity of AT or blood lactate concentration can be related to different species of animals (Billat et al. 2003; Abreu et al. 2016), strains (Billat et al. 2005; Almeida et al. 2013), ergometers (Manchado et al. 2006b), ages (Cunha et al. 2009) and genders (Billat et al. 2005). Concerning the genders, the variations phenotypic and genetic have been linked to the different cardiovascular adaptations and aerobic capacity (Konhilas et al. 2004; De Bono et al. 2006), that are important factors in exercise performance (Konhilas et al. 2004). However, the mechanisms for these differences remain unknown, which makes it important to propose evaluation methods for mice considering both genders.

Among the main evaluation protocols for measuring AT, maximal lactate steady state (MLSS) is considered to be the gold-standard test for measuring aerobic capacity (Beneke 2003). At MLSS intensity occurs the balance between production and removal of blood lactate, being an important marker of energy expended during the efforts (Beneke 2003; Billat et al. 2003; Faude et al. 2009). Furthermore, the MLSS has been applied with success in rats (Manchado et al. 2006a; Gobatto et al. 2009, Cunha et al. 2009, Almeida et al. 2013) and mice (Gobatto et al. 2001, Ferreira et al, 2010; Almeida et al. 2011; de Araujo et al. 2015), with benefic training effects on this intensity (Almeida et al. 2014; Petriz et al. 2015). However, the determination of 
the MLSS intensity requires several effort sessions in different days and many sampling of blood, which limits the application of this test according the experimental design.

On the other hand, based on the theory of MLSS and blood lactate clearance, Tegtbur et al. (1993) proposed the lactate minimum test (LM), which could estimate in a single day of effort the intensity related to intensity of MLSS. This test consists of a supramaximal exercise for hyperlactatemia induction, rest period and incremental phase during metabolic acidosis. The minimum point of the curve between blood lactate concentrations versus intensities is known as intensity of LM. The LM has been applied with success for humans (Jones et al. 1998; MacIntosh et al. 2002; Pardono et al. 2008; Simões et al. 2009; Sotero et al. 2009; Knoepfli-Lenzin and Boutellier 2011), horses (Gondim et al. 2007; Miranda et al. 2014) and rats (de Araujo et al. 2007; de Araujo et al. 2012; Voltarelli et al. 2002), though a mouse protocol remains to be established.

Considering the importance of evaluation methods to determine the individual intensity of AT for controlling the load (product intensity by volume) (Mujika et al. 1995) during exercise, and several applications of mouse models in research on health and metabolism (Levin 2008; Stanford et al. 2015; Garton et al. 2016), we sought to validate the LM protocol for swimming mice. The analyses consisted in investigating the relationship among intensities of LM and MLSS and the differences between genders with respect to aerobic capacity.

\section{Methods}

\section{Animals}

Nineteen Swiss mice (male $n=10$; female $n=9$ ) provided by the University of Campinas Animal Breeding Center (CEMIB, Brazil) were submitted to swimming exercise tests. The experimental procedures started with untrained adult mice at 12 weeks old, which are not affected by senescence (Flurkey et al., 2007), ranging from 33-40 $\mathrm{g}$ (male) and 27-33 $\mathrm{g}$ (female) at the beginning, and 35-42 $\mathrm{g}$ (male) and 29-35 $\mathrm{g}$ (female) at the end of the study. Animals remained on a $12 \mathrm{~h}$ light-dark cycle and had access to food (commercial rodent chow) and water ad libitum. Groups of five animals were housed indoors $\left(22 \pm 1^{\circ} \mathrm{C}\right)$ in propylene cages maintained on ventilated shelves. Body mass was determined daily before exercise protocol. All experiments https://mc06.manuscriptcentral.com/apnm-pubs 
followed the Guide for the Care and Use of Laboratory Animals published by National Institute of Health and the guidelines of the Brazilian College for Animal Experimentation. The study was approved by Ethics Committee on the Use of Animals (University of Campinas 3913-1).

\section{Experimental protocol}

\section{Adaptation to water}

For all procedures, the load was expressed as the equivalent percentage of body mass $(\% \mathrm{bm})$ for each animal. This load was built with lead and latex elastic that were tied to the animal's back. All mice were adapted to water $\left(31 \pm 1^{\circ} \mathrm{C}\right)$ before the beginning of the experiment during a period of 14 uninterrupted days. For first 3 days, mice were initially inserted in shallow water $(3 \mathrm{~cm})$ for $15 \mathrm{~min}$. At $4^{\text {th }}$ day, each mouse swam in deep water $(100 \mathrm{~cm})$ for $2 \mathrm{~min}$ with an increment of $2 \mathrm{~min} /$ day until the $8^{\text {th }}$ day of procedure. The intensity with which mice started to swim was considered with respect to body mass $(\% \mathrm{bm})$. On the $9^{\text {th }}$ day, the animals were submitted to swimming exercise for 5 min to support an intensity equivalent to $3 \% \mathrm{bm}$. Following that, at each day the animals were submitted to different intensity and periods of swimming exercise $(5 \%$ bm for 3 min, $9 \% \mathrm{bm}$ for $1 \mathrm{~min}, 11 \% \mathrm{bm}$ for $1 \mathrm{~min}, 13 \% \mathrm{bm}$ for $30 \mathrm{~s}$ and $15 \% \mathrm{bm}$ for $30 \mathrm{~s}$, respectively), always followed by another session of $5 \mathrm{~min}$ without intensity. The adaptation features are designed so that the animal is familiar with manipulation, imposed intensity and water, in order to reduce the stress caused by these factors during the evaluation. Similar adaptation protocol has been used in rodents in previous studies carried out in our laboratory, and it was suggested that it reduces the stress, without promoting physical training adaptations (Gobatto et al., 2001; Manchado et al., 2006a).

\section{Lactate Minimum Test (LM)}

For determination of LM intensity in mice, the standardized protocol of LM was used in accordance with the methods proposed for rats by Araujo et al. (2007). The LM were performed in individual cylindrical tanks $(30 \mathrm{~cm}$ diameter $\times 120 \mathrm{~cm}$ depth), filled with water $(100 \mathrm{~cm})$. The supramaximal exercise for hyperlactatemia induction consisted of: $30 \mathrm{~s}$ of exercise $(13 \% \mathrm{bm}), 30 \mathrm{~s}$ of passive recovery and an exercise bout until exhaustion $(13 \% \mathrm{bm})$. This protocol of hyperlactatemia induction presented a higher success rate for https://mc06.manuscriptcentral.com/apnm-pubs 
the determination of individual intensity of LM (Araujo et al. 2007). Exhaustion was assumed when the animal was unable to stay on the water surface for $10 \mathrm{~s}$ (McArdle and Montoye 1966; de Araujo et al. 2007). During rest, the mice stayed in shallow water to avoid thermal stress. At that point, a blood sample was collected, from a small cut at the extremity of the tail, more than $9 \min$ post-exercise. The 9 min recovery time was tested by Voltarelli et al. (2002) as the period for occur the peak of blood lactate. Following, an incremental test was performed with intensities of 4.0, 4.5, 5.0, 5.5, 6.0 and 7.0\% bm. Each stage lasted $5 \mathrm{~min}$, separated by $30 \mathrm{~s}$ for blood sampling. The degree of fitting of the U-shaped relationship among blood lactate concentrations (mmol. $\left.\mathrm{L}^{-1}\right)$ versus intensities $(\% \mathrm{bm})$ of incremental phase was determined by a second order polynomial. The LM intensity corresponding to the minimum point or derived zero of the curve (Figure 1). The criterion to determine the success rate of the LM was the presence of the U- shaped $(a>0)$ and coefficient of determination $\left(\mathrm{R}^{2}\right)$ of the curve higher than 0.8 (de Araujo et al., 2007; de Araujo et al., 2012; Voltarelli et al., 2002).

\section{INSERT FIGURE 1 HERE}

\section{Maximal Lactate steady state (MLSS)}

The MLSS intensity was defined as the highest intensity that can be maintained during the exercise with blood lactate stabilization (Beneke 2003; Heck et al., 1985). All mice were submitted individually to $30 \mathrm{~min}$ continuous exercise. The first intensity tested corresponded to individuals intensities of LM and subsequently, for other efforts, the load increments were of $0.5 \% \mathrm{bm}$. The blood samples $(15 \mu \mathrm{L}$ collected from the tail) were collected at rest, $10^{\text {th }}$ and $30^{\text {th }} \mathrm{min}$, however the mice were removed from the water every 5 min for $30 \mathrm{~s}$ to mimic previous studies in which the blood samples were collected in this moments (Gobatto et al., 2001; Gobatto et al., 2009; Voltarelli et al., 2002). For this determination, it was necessary at least 2 days and at maximum 5 days, with $48 \mathrm{~h}$ between them. The criterion to determine the MLSS intensity was the highest 
intensity in which blood lactate concentration increases less than $1 \mathrm{mmol}^{-1}$ between $10^{\text {th }}$ and $30^{\text {th }}$ min of exercise (Beneke 2003).

\section{Blood samples and analysis}

For determination of the blood lactate concentrations, blood samples $(15 \mu \mathrm{L})$ were collected using heparinized capillary tubes and transferred to microcentrifuge tubes $(1.5 \mathrm{~mL})$ containing trichloroacetic acid at $4 \%(240 \mu \mathrm{L})$. The sample were centrifuged for $3 \mathrm{~min}(3000 \mathrm{rpm})$ and $50 \mu \mathrm{L}$ of plasma was placed into microplate. The following reagent $(250 \mu \mathrm{L})$ was added: glycine/EDTA, hydrazine hydrate $24 \%$, lactate dehydrogenase and b-nicotinamide adenine dinucleotide. The homogenized sample and reagent were incubated for 60min, and absorbance was determined by spectrophotometer analysis (Asys Expert Plus) at $340 \mathrm{~nm}$. The enzymatic analysis for determine blood lactate concentration was described by Engel and Jones 1978.

\section{Statistical Analysis}

The results are presented as mean \pm standard deviation. The statistic procedure consisted of two-way Anova for repeated measures (factors: genders versus protocol) to compare LM and MLSS and one-way Anova to compare body mass. The Scheffe post-hoc comparison was used to identify differences among intensities and blood lactate concentrations. The effect size was calculated based on d-Cohen's and used to identify the magnitude of the differences. The effect size (ES) obtained in the statistical analysis was interpreted as proposed by Hopkins et al. (2009,) with ES $<0.2$ considered as trivial, $0.2-0.5$ considered as small, 0.6-1.1 considered as moderate, 1.2-1.9 considered as large, and $>2.0$ considered as very large. The Bland and Altman analysis (bias [ \pm 95 confidence interval]) was used to identify the differences between MLSS and LM (Bland and Altman 1999).

The variability of the intensities was determined using box-plot analysis. On each box, the central mark is the median $\left(50^{\text {th }}\right.$ percentile $)$, the edges of the box are the quartiles $\left(25^{\text {th }}\right.$ and $75^{\text {th }}$ percentiles $)$ and the whiskers extremes are maximum and minimum values. The dispersion of the intensities was calculated by difference between quartiles. Pearson's correlations (r) were used to determine the relation between the intensities and a 
linear regression $\pm 95 \%$ confidence interval analysis were performed. Correlations were interpreted based on Cohen's scale of magnitudes (Cohen 1988) comprising 0.1 (small), 0.3 (moderate), and 0.5 (large), augmented (Hopkins et al., 2009) to include 0.7 (very large) and $>0.9$ (nearly perfect). In all cases, the statistical significance was set at $\mathrm{P} \leq 0.05$.

\section{Results}

The LM presented a success rate of $89.5 \%$ for all mice $(n=17)$ from criterions determined $\left(R^{2}>0.8\right.$ and U-shaped curve), while male were $90 \%(n=9)$ and female were $88 \%(n=8)$. Differences were found among intensities of LM and MLSS for all mice (Table 1). The intensities of LM were lower than intensities of MLSS (5.18\% bm versus $6.34 \% \mathrm{bm}, P<0.001, \mathrm{~F}=78.96)$, with a large effect size (ES=1.34), underestimating MLSS in $17.6 \%$ for all mice (male: 13.5\%; female: $21.6 \%$ ). Nonetheless, correlation analysis between protocol tests showed a very large and significant relationship $(\mathrm{r}=0.78, p<0.001)$ (Figure 3$)$. The same results were obtained when the protocols were analyzed separately for each gender (Table 1). The intensities of LM were lower than intensity of MLSS for males and females $(P=0.002 ; P<0.001)$, and the magnitudes of ES emphasized these differences among intensities. The differences among females were large (ES=1.76); the differences among males were moderate $(\mathrm{EF}=1.13)$. The blood lactate concentrations was lower in the $\mathrm{LM}$ test as compared to the MLSS test for all groups of mice $(P=0.01)$ as well as for females $(P=0.01)$. This trend did not hold for male mice $(P=0.23)$

\section{INSERT TABLE 1 HERE}

Mice presented a large dispersion of intensities in both evaluations protocols (Figure 2). The dispersion of intensities to male were of $0.6 \% \mathrm{bm}$ (LM) and $1.19 \% \mathrm{bm}$ (MLSS), while for female were of $1.01 \% \mathrm{bm}$ (LM) and1.02\% bm (MLSS). Overall, a higher dispersion of the intensities occurs below of median values to

both protocols. The extremes points (maximum and minimum) provide the range of intensities supported by animals. The range of LM intensity was of 4.00 to $6.20 \% \mathrm{bm}$ (male) and 4.38 to $6.39 \% \mathrm{bm}$ (female), while the 
range of MLSS intensity was of 4.24 to $7.0 \% \mathrm{bm}$ (male) and 5.38 to $8.39 \% \mathrm{bm}$ (female). Comparisons between genders for a given evaluation (e.g., intensities of LM male versus LM female and MLSS male versus MLSS female) showed no significant difference (Figure 2). Significant differences were only re observed among LM intensities for males versus MLSS intensities for females, with higher intensities supported by females versus males $(P<0.001)$.

\section{INSERT FIGURE 2 HERE}

Furthermore, the ANOVA analysis showed an effect of gender over protocols tests with a significance interaction among them $(P=0.022, F=6.28)$, thus, different relationships of intensities are expected for male and female. Small magnitude was observed in relationship among body mass (g) and intensities (LM and MLSS) and the correlation did not present significant difference (Table 2). Nevertheless, when correlations among intensities of LM and MLSS were separately tested to each genders (Figure 3), a significant and large relationship for male $(\mathrm{r}=0.67, p=0.033)$ and very large relationship for female $(\mathrm{r}=86, p=0.003)$ were determined.

\section{INSERT FIGURE 3 HERE}

\section{INSERT TABLE 2 HERE}

Additionally, the Bland and Altman analysis showed a lower bias for male than female and for both was found a wide limit of agreement (Figure 4). The comparison among intensities of MLSS and LM for male (Figure 4) presented values of bias of $0.84(1.24) \% \mathrm{bm}$, while for female (Figure 4) the values were of 1.5(0.98) $\% \mathrm{bm}$. For all mice (Figure 4), the value of bias was $1.15(1.27 \%)$. Furthermore, for male the distribution of points was closely of mean intensity, different of that occurred for females. 


\section{INSERT FIGURE 4 HERE}

\section{Discussion}

The main finding of this study was that intensity obtained in the LM protocol underestimates the intensity of MLSS by $17.6 \%$ for all mice (male: 13.5\%; female: $21.6 \%$ ). The intensities of LM and MLSS presented strong correlations for both genders (male $[\mathrm{r}=0.67]$; female $[\mathrm{r}=0.86]$ ); however, the LM value was not in agreement with the MLSS value. Nevertheless, the analysis of agreement showed that bias was higher for females $(1.5[0.98] \% \mathrm{bm})$, this bias represents a magnitude about $50 \%$ within of the range of means intensities observed between protocols $(4.5-7.5 \% \mathrm{bm})$. For males, a lower bias was found (0.84 [1.24] \% bm), and this bias represents a magnitude about $42 \%$ within of the range of mean intensities between protocols $(4.4-6.4 \%$ bm). Based on these results, the LM protocol tested could be used to estimate individual intensity of aerobic capacity for male mice, with lower error associated with the intensities of MLSS as compared to females.

Our study is the first to propose validation of the LM protocol for swimming mice with a consideration of gender. This rodent model is widely used in researches related to health and metabolism associated to exercise which acts as non-drug intervention able to modulate different responses into the organism (Levin 2008; Stanford et al. 2015; Garton et al. 2016). Araujo et al. (2007) standardized the LM protocol for swimming rats comparing four protocols for hyperlactatemia induction. The success rate among them were different (58\%; $55 \% ; 80 \%$ and $91 \%)$ considering the conditions: polynomial fit $\left(\mathrm{R}^{2}>0.08\right)$ and U-shaped curve (blood lactate concentration versus intensities). We tested the same protocol that obtained higher success (30 s of exercise $(13 \% \mathrm{bm}), 30 \mathrm{~s}$ of passive recovery and exercise bout until exhaustion $(13 \% \mathrm{bm})$, due to better assurance for 
the LM identification, finding also a high success rate in the determination of intensity of LM (all mice: $89.5 \%$, male: $90 \%$, female: $88 \%$ ).

Although our study found that LM underestimates MLSS for mice, de Araujo et al. (2007) found that intensity as obtained with the LM protocol $(5.06 \pm 0.93 \% \mathrm{bm})$ accurately represented intensity of MLSS $(5.3 \pm$ $0.5 \%$ ) for rats. The same conclusion was reported earlier by Voltarelli et al. (2002), in which found intensity of LM of $4.95 \pm 0.1 \% \mathrm{bm}$ to swimming rats. These authors proposed a hyperlactatemia induction protocol with 6min exercise interval (6 x $30 \mathrm{~s}$ jump into the water and $30 \mathrm{~s}$ rest), however this protocol was tested posteriorly to success rate and did not present a suitable percentage for LM identification (de Araujo et al., 2007). For both studies presented were used 9 min of recovery time and the incremental test $(4.0,4.5,5,5.5,6$ and $7 \%$ bm for 5 min in each one), and we kept the same protocols. Nevertheless, the LM intensities obtained in our study were slightly higher than both studies (Table 1).

The MLSS protocol, which is considered as the gold-standard to determine AT, consisted of subsequent session of exercise, adding each trial an intensity increment to find the highest intensity that occur the balance between production and removal of blood lactate (Beneke 2003). In our study, the intensity increment used to identify MLSS intensity was of $0.5 \% \mathrm{bm}$, while in study of Voltarelli et al. 2002, the intensity increment was of $1 \%$ down and $1.5 \%$ upper the LM intensity, the choice by lower intensity increment can improve the accuracy to determine the intensity of AT. Considering that the overall dispersion of the intensities of LM and MLSS found for our study were about of $1 \% \mathrm{bm}$ (Figure 2), if the choice was an intensity increment higher $(>0.5 \%$ $\mathrm{bm})$ it was possible that occur alterations in the relationship among the intensities of the protocols due to lack of precision.

The LM had been used as a good evaluation protocol to estimate intensity of MLSS in humans (Jones et al. 1998; MacIntosh et al. 2002; Simões et al. 2009; Pardono et al. 2008; Sotero et al. 2009; Knoepfli-Lenzin and Boutellier al. 2011), horses (Gondim et al. 2007; Miranda et al. 2014) and as discussed in rats (de Araujo et al. 2007; de Araujo et al. 2012; Voltarelli et al. 2002). Nevertheless, another studies also found that LM intensity underestimate the MLSS intensity (Carter et al. 1999; Ribeiro et al. 2009; Labruyere and Perret 2012; Zagatto et 
al. (2014)) and the reason for this could be associated to specific phases of the LM (hyperlactatemia induction, resting pause and incremental test).

Specifics phases of the LM could modifying the relationship between production and clearance of lactate, promoting a left displacement of the lactate curve and underestimating the LM intensity (Heck et al. 1991; Carter et al. 1999; Ribeiro et al. 2009; Labruyere and Perret 2012; Perret et al. 2012). Recently, Zagatto et al. (2014) verified differences between intensity of LM determined after different ways of hyperlactatemia induction in cycling, attesting that blood acid-base balance during resting pause can alters the response of incremental phase. Perret et al. (2012) evaluated athletes using LM and MLSS and they found a strong relationship among them, but LM intensity lower than MLSS intensity. These authors suggest that lower blood lactate concentration before the incremental phase associated to individual characteristics of subject such as higher aerobic capacity and higher blood lactate clearance could underestimate LM. Thus, the relationship between LM and MLSS seems controversial, being important the standardization of evaluation protocols.

The wide variability of the individual intensities can be observed in our study for both evaluation protocols (Figure 2). In a study with swimming mice, Gobatto et al. (2009) found mean intensity of MLSS of $4.6 \% \mathrm{bm}$, however intensities varied from 3 to $7 \% \mathrm{bm}$, being that about $44 \%$ of the mice supported intensities of MLSS $\geq 5 \% \mathrm{bm}$. This large range of intensities (Gobatto et al., 2009) supports our results for male and female mice; however, the females presented higher intensities for both evaluation protocols (reaching about $8 \%$ bm with the MLSS protocol). Nonetheless, the comparison between genders did not reveal differences between males and females for a given evaluation protocol, probably due to the broad dispersion of the intensities measured. For practical applications, the significance (P values) of these findings does not seem to represent real differences between genders (Baker 2016), since higher intensities could be observed when we evaluated females.

Other important found of this study is the significant interaction of genders between protocols, wherein the relation of the intensities obtained in both protocols changes when it is evaluated males and females. It is possible that gender-based differences in body composition may have affected the intensity values; however, there was no significant correlation among intensities of LM and MLSS, and body mass (Table 2). In contrast, 
Almeida et al. (2011) used MLSS to compare mouse strains (ob/ob versus ob/OB) with regard to swimming exercise. They found a mean intensity of $4.3 \% \mathrm{bm}$ versus $3.2 \% \mathrm{bm}$ for ob/ob and ob/OB respectively. The difference in the body composition is related to large amount of adipose tissue found in the ob/ob mice that present leptin deficiency. Thus, the authors discuss about the facilitation in the fluctuation associated to the body composition that not necessarily represent a greater physical condition relative to aerobic capacity.

The study of Hoydal et al. (2007) showed that the female mice presented higher weekly rate of $\mathrm{VO}_{2 \max }$ increase than male $\left(4.8\right.$ versus $\left.2.9 \mathrm{ml} / \mathrm{kg}^{0.75}\right)$ and higher running speed. De Bono et al. (2006) also found that female mice ran $40 \%$ more than male mice. Moreover, others evidence suggest that the female present a better aerobic condition related to oxygen consumption, mitochondrial adaptations, signaling pathways (e.g. MAPK) and cardiac adaptations than male (Konhilas et al. 2004; Dworatzek et al. 2014). Based on the results presented here, it appears that females present higher aerobic capacity than males; however, additional investigations should be carried out to understand gender-based differences during exercise.

Different blood lactate concentrations are observed depending on the species (rats or mice), type of exercise (running or swimming) and type of method (exhaustive or non-exhaustive). Our study presented lower values of concentration compared with other studies that evaluated aerobic capacity. For swimming rats were observed about 5 mmol.L ${ }^{-1}$ (Gobatto et al. 2001; Manchado et al. 2006a; de Araujo et al. 2007) and running rats

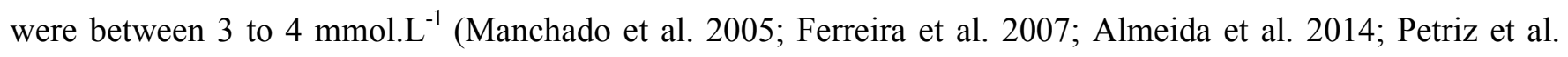
2015). For swimming mice, the range varied between 4 to $6.5 \mathrm{mmol} \mathrm{L}^{-1}$ (Gobatto et al. 2009; de Araujo et al. 2015), while running mice was 3 mmol.L $\mathrm{L}^{-1}$ (Ferreira et al. 2007). These different results can be related to the ergometer (Manchado et al. 2006b) and individual characteristics of the species (Abreu et al. 2016). Factors as skeletal muscle recruited, type of fibers and muscles oxidative capacity, as well body size and composition, oxygen consumption and trainability, suggest different stabilization intensities and clearance rates of blood lactate (Billat et al. 2003; Hoydal et al. 2007; Brooks 2009).

Thus, the LM protocol tested in our study underestimated the intensity of MLSS for both genders. Future studies should investigate another protocol with changes in the specific phases (hyperlactatemia induction, resting pause and incremental test) to characterize the relationship to LM intensity. The present study 
began the investigation into gender-based differences in exercise intensity. It remains to be determined whether these gender-based differences are due exclusively to body mass.

In summary, the present study proposed to validate the LM protocol for swimming mice, due to possibility to estimate in one session test the intensity of MLSS. However, the LM protocol tested underestimated the MLSS for both genders. For practical applications, the bias associated was lower for males vs. females; thus, the LM protocol could be used to determine individual aerobic capacity of exercise for male mice. It is necessary more studies about the standardization evaluation protocols for mice, considering several applications such as nutrition, pathologies and metabolism.

\section{Conflict of interest}

The authors have no conflict of interest associated with this manuscript.

\section{Acknowledgment}

The authors would like to thank FAPESP (Proc. no. 2015/00272-6) and CNPq (proc. no. 302827/2015-3 and 442934/2014-9) for the financial support.

\section{References}

Abreu, P., Mendes, S.V., Leal-Cardoso, J.H., and Ceccatto, V.M. 2016. Anaerobic threshold employed on exercise training prescription and performance assessment for laboratory rodents: A short review. Life Sci. 151: 1-6. PMID: 26860893

Almeida, J.A., Petriz, B.A., Gomes, C.P., Rocha, L.A., Pereira, R.W., and Franco, O.L. 2013. Determination of the maximal lactate steady state in obese Zucker rats. Int. J. Sports Med. 34(3): 214-7. PMID: 22972243

Almeida, J.A., B, A.P., Gomes, C.P., Araujo, R.C., Pereira, R.W., and Franco, O.L. 2014. Exercise training at MLSS decreases weight gain and increases aerobic capacity in obese Zucker rats. Int. J. Sports Med. 35(3): 199-202. PMID: 23900899 
Almeida, W.S., Lima, L.C., Cunha, V.N., R, R.C., Araujo, R.C., Barros, C.C., Simoes, H.G., and Campbell, C.S. 2011. Assessment of aerobic capacity during swimming exercise in ob/ob mice. Cell. Biochem. Funct. 29(8): 666-672. PMID: 22031235

Baker, M. 2016. Statisticians issue warning over misuse of P values. Nature. 531(7593): 151. PMID: 26961635

Beneke, R. 2003. Methodological aspects of maximal lactate steady state-implications for performance testing. Eur. J. Appl. Physiol. 89(1): 95-99.PMID: 12627312

Billat, V.L., Sirvent, P., Py, G., Koralsztein, J.P., and Mercier, J. 2003. The concept of maximal lactate steady state: a bridge between biochemistry, physiology and sport science. Sports Med. 33(6): 407-426. PMID: 12744715

Billat, V.L., Mouisel, E., Roblot, N., and Melki, J. 2005. Inter- and intrastrain variation in mouse critical running speed. J. Appl. Physiol. 98(4): 1258-63. PMID: 15542571

Bland, J.M. and Altman, D.G. 1999. Measuring agreement in method comparison studies. Stat. Methods Med. Res; 8(2): 135-160. PMID: 10501650

Brooks, G.A. 2009. Cell-cell and intracellular lactate shuttles. J. Physiol. 587: 5591-5600. PMID:19805739

Carter, H., Jones, A.M., and Doust, J.H. 1999. Effect of incremental test protocol on the lactate minimum speed. Med. Sci. Sports Exerc. 31 (6): 837-845. PMID: 10378911

Cohen, J. 1988. Statistical power analysis for the behavioral sciences. Hillsdale, N.J.: L. Erlbaum Associates.

Cunha, R.R., Cunha, V.N., Segundo, P.R., Moreira, S.R., Kokubun, E., Campbell, C.S., de Oliveira, R.J., and Simoes, H.G. 2009. Determination of the lactate threshold and maximal blood lactate steady state intensity in aged rats. Cell Biochem. Funct. 27(6): 351-7. PMID: 19585487

De Araujo, G.G., Gobatto, C.A., de Barros Manchado-Gobatto, F.B., Teixeira, L.F., Dos Reis, I.G., Caperuto, L.C., Papoti, M., Bordin, S., Cavaglieri, C.R., and Verlengia, R. 2015. MCT1 and MCT4 kinetic of mRNA expression in different tissues after aerobic exercise at maximal lactate steady state workload. Physiol. Res. 64(4): 513-22. PMID: 25470525

De Araujo, G.G., Papoti, M., Delbin, M.A., Zanesco, A., and Gobatto, C.A. 2013. Physiological adaptations during endurance training below anaerobic threshold in rats. Eur. J. Appl. Physiol. 113(7): 1859-1870. PMID: 23456272

De Araujo, G.G., Papoti, M., Dos Reis, I.G., de Mello, M.A., and Gobatto, C.A. 2012. Physiological responses during linear periodized training in rats. Eur J Appl Physiol. 112(3): 839-52. PMID: 21681481

De Araujo, G.G., Papoti, M., Manchado, F.B., de Mello, M.A., and Gobatto, C.A. 2007. Protocols for hyperlactatemia induction in the lactate minimum test adapted to swimming rats. Comp. Biochem. Physiol. A Mol. Integr. Physiol. 148(4): 888-892. PMID:17964836

De Bono J.P., Adlam D., Paterson D.J., Channon K.M. 2006. Novel quantitative phenotypes of exercise training in mouse models. Am. J. Physiol. Regul. Integr. Comp. Physiol. 290(4): 926-934. PMID: 16339385

Dworatzek, E., Mahmoodzadeh, S., Schubert, C., Westphal, C., Leber, J., Kusch, A., Kararigas, G., Fliegner, D., Moulin, M., Ventura-Clapier, R., Gustafsson, J.A., Davidson, M.M., Dragun, D., and Regitz-Zagrosek, V. 2014. Sex differences in exercise-induced physiological myocardial hypertrophy are modulated by oestrogen receptor beta. Cardiovasc. Res. 102(3): 418-428. PMID: 24654233

Engel, P.C. and Jones, J.B. 1978. Causes and elimination of erratic blanks in enzymatic metabolite assays involving the use of NAD+ in alkaline hydrazine buffers: improved conditions for the assay of L-glutamate, L-lactate, and other metabolites. Anal. Biochem. 88(2): 475-484. PMID: 29519

Faude, O., Kindermann, W., and Meyer, T. 2009. Lactate threshold concepts: how valid are they? Sports Med. 39(6): 469-490. PMID: 19453206 
Ferreira, J.C., Bacurau, A.V., Bueno, C.R., Jr., Cunha, T.C., Tanaka, L.Y., Jardim, M.A., Ramires, P.R., and Brum, P.C. 2010. Aerobic exercise training improves $\mathrm{Ca} 2+$ handling and redox status of skeletal muscle in mice. Exp. Biol. Med (Maywood). 235(4): 497-505. PMID: 20407082

Ferreira, J.C., Rolim, N.P., Bartholomeu, J.B., Gobatto, C.A., Kokubun, E., and Brum, P.C. 2007. Maximal lactate steady state in running mice: effect of exercise training. Clin Exp Pharmacol Physiol. 34(8): 760-5. PMID: 17600553

Fisher, G., Brown, A.W., Bohan Brown, M.M., Alcorn, A., Noles, C., Winwood, L., Resuehr, H., George, B., Jeansonne, M.M., and Allison, D.B. 2015. High Intensity Interval- vs Moderate Intensity- Training for Improving Cardiometabolic Health in Overweight or Obese Males: A Randomized Controlled Trial. PLoS One. 10(10): e0138853. PMID: 26489022

Flurkey, K., Currer J. M., and Harrison, D.E. 2007. The Mouse in Aging Research. In The Mouse in Biomedical Research. Edited by J.G. Fox. American College Laboratory Animal Medicine (Elsevier), Burlington, MA. pp. 637-672.

Garton, F.C., North, K.N., Koch, L.G., Britton, S.L., Nogales-Gadea, G., and Lucia, A. 2016. Rodent models for resolving extremes of exercise and health. Physiol. Genomics. 48(2): 82-92. PMID: 26395598

Gobatto, C.A., de Mello, M.A., Sibuya, C.Y., de Azevedo, J.R., dos Santos, L.A., and Kokubun, E. 2001. Maximal lactate steady state in rats submitted to swimming exercise. Comp. Biochem. Physiol. A Mol. Integr. Physiol. 130(1): 21-27. PMID: 11672680

Gobatto, C.A., Manchado-Gobatto, F.B., Carneiro, L.G., de Araujo, G.G., and dos Reis, I.G. 2009. Maximal lactate steady state for aerobic evaluation of swimming mice. Comparative Exercise Physiology. 6(3): 99-103. DOI: $10.1017 / \mathrm{S} 1755254009990109$

Gondim, F.J., Zoppi, C.C., Pereira-da-Silva, L., and de Macedo, D.V. 2007. Determination of the anaerobic threshold and maximal lactate steady state speed in equines using the lactate minimum speed protocol. Comp. Biochem. Physiol. A Mol. Integr. Physiol. 146(3): 375-80. PMID: 17234441

Heck, H., Rosskopf, P., Hirsch, A., Hoberg, T., Hoppe, W. and Reichwein, R. 1991. The effect of pre exercise lactate, duration of break, and the increase of workload on the lactate turn point. Deutsch. Z. Sportmed. 42: 248-263. PU: 199604107470

Heck, H., Mader, A., Hess, G., Mücke, S., Müller, R. and Hollmann, W., 1985. Justification of the 4-mmol/L lactate threshold. Int. J. Sports Med. 6(3): 117-130. PMID: 4030186

Hoydal, M.A., Wisloff, U., Kemi, O.J., and Ellingsen, O. 2007. Running speed and maximal oxygen uptake in rats and mice: practical implications for exercise training. Eur. J. Cardiovasc. Prev. Rehabil. 14(6): 753-760. PMID: 18043295

Hopkins, W.G., Marshall, S.W., Batterham, A.M., and Hanin, J. 2009. Progressive statistics for studies in sports medicine and exercise science. Med. Sci. Sports Exerc. 41(1): 3-13. PMID: 19092709

Jones, A.M. and Doust, J.H. 1998. The validity of the lactate minimum test for determination of the maximal lactate steady state. Med. Sci. Sports Exerc. 30(8): 1304-1313. PMID: 9710874

Kang, S., Kim, K.B., and Shin, K.O. 2013. Exercise training improves leptin sensitivity in peripheral tissue of obese rats. Biochem. Biophys. Res. Commun .435(3): 454-459. DOI: 101016/ S0006291X13007778

Kemi, O.J., Loennechen, J.P., Wisloff, U., and Ellingsen, O. 2002. Intensity-controlled treadmill running in mice: cardiac and skeletal muscle hypertrophy. J. Appl. Physiol. 93(4): 1301-9. PMID: 12235029

Knoepfli-Lenzin, C. and Boutellier, U. 2011. Lactate minimum is valid to estimate maximal lactate steady state in moderately and highly trained subjects. J. Strength Cond. Res. 25(5): 1355-1359. PMID: 21522075

Konhilas, J.P., Maass, A.H., Luckey, S.W., Stauffer, B.L., Olson, E.N., and Leinwand, L.A. 2004. Sex modifies exercise and cardiac adaptation in mice. Am. J. Physiol. Heart Circ. Physiol. 287(6): 2768-2776. PMID: 15319208 
Levin, B.E. 2008. Epigenetic influences on food intake and physical activity level: review of animal studies. Obesity (Silver Spring). 16(3): 51-54. DOI: 10.1038/oby.2008.518

Little, J.P., Safdar, A., Bishop, D., Tarnopolsky, M.A., and Gibala, M.J. 2011. An acute bout of high-intensity interval training increases the nuclear abundance of PGC-1alpha and activates mitochondrial biogenesis in human skeletal muscle. Am. J. Physiol. Regul. Integr. Comp. Physiol. 300(6): 1303-1310. PMID: 21451146

Labruyere, R. and Perret, C. 2012. The level of lactic acidosis affects lactate minimum in a heart rate-based lactate minimum test. Int. J. Sports Med. 33(11): 898-902. PMID: 22791618

McArdle, W.D. and Montoye, H.J. 1966. Reliability of exhaustive swimming in the laboratory rat. J. Appl. Physiol. 21(4): 1431-1434. PMID: 5916692

MacIntosh, B.R., Esau, S., and Svedahl, K. 2002. The lactate minimum test for cycling: estimation of the maximal lactate steady state. Can. J. Appl. Physiol. 27(3): 232-249. PMID: 12180316

Manchado, F.B., Gobatto, C.A., Contarteze, R.V.L., Papoti, M. and Mello, M.A.R. 2005. Maximal lactate steady state in running rats. J. Exerc. Physiol. 8(5): 29-35.

Manchado, F. de B., Gobatto, C.A., Voltarelli, F.A., and Mello, M.A.R. 2006a. Non-exhaustive test for aerobic capacity determination in swimming rats. Appl. Physiol. Nutr. Metab. 31(6): 731-736. PMID: 17213888

Manchado, F.B., Gobatto, C.A., Contarteze, R.V.L., Papoti, M. and Mello, M.A.R. 2006b. Máxima fase estável de lactato é ergômetro-dependente em modelo experimental utilizando ratos. Rev. Bras. Med. Esporte. 12(5): 259-262.

Miranda, M.C., Queiroz-Neto, A., Silva-Junior, J.R., Pereira, M.C., Soares, O.A., Borghi, R.T., and Ferraz, G.C. 2014. Comparison of the lactate minimum speed and the maximal lactate steady state to determine aerobic capacity in purebred Arabian horses. N. Z. Vet. J. 62(1): 15-20. PMID: 23869425

Mujika, I., Chatard, J.C., Busso, T., Geyssant, A., Barale, F., and Lacoste, L. 1995. Effects of training on performance in competitive swimming. Can. J. Appl. Physiol. 20(4): 395-406. PMID: 8563672

Pardono, E., Sotero, R.C., Hiyane, W., Mota, M.R., Campbell, C.S., Nakamura, F.Y., and Simoes, H.G. 2008. Maximal lactate steady-state prediction through quadratic modeling of selected stages of the lactate minimum test. J. Strength Cond. Res. 22(4): 1073-80. PMID: 18545205

Perret, C., Labruyere, R., Mueller, G., and Strupler, M. 2012. Correlation of heart rate at lactate minimum and maximal lactate steady state in wheelchair-racing athletes. Spinal Cord. 50(1): 33-6. PMID: 21894166

Petriz, B.A., Almeida, J.A., Gomes, C.P., Ernesto, C., Pereira, R.W., and Franco, O.L. 2015. Exercise performed around MLSS decreases systolic blood pressure and increases aerobic fitness in hypertensive rats. BMC Physiol. 15: 1. PMID: 25888441

Ribeiro, L.F., Goncalves, C.G., Kater, D.P., Lima, M.C., and Gobatto, C.A. 2009. Influence of recovery manipulation after hyperlactemia induction on the lactate minimum intensity. Eur. J. Appl. Physiol. 105(2): 159-65. PMID: 18853175

Schjerve, I.E., Tyldum, G.A., Tjonna, A.E., Stolen, T., Loennechen, J.P., Hansen, H.E., Haram, P.M., Heinrich, G., Bye, A., Najjar, S.M., Smith, G.L., Slordahl, S.A., Kemi, O.J., and Wisloff, U. 2008. Both aerobic endurance and strength training programmes improve cardiovascular health in obese adults. Clin. Sci. 115(9): 283-293. PMID: 18338980

Smith-Ryan, A.E., Melvin, M.N., and Wingfield, H.L. 2015. High-intensity interval training: Modulating interval duration in overweight/obese men. Phys. Sportsmed. 43(2): 107-113. PMID: 25913937

Sotero, R.C., Pardono, E., Landwehr, R., Campbell, C.S., and Simoes, H.G. 2009. Blood glucose minimum predicts maximal lactate steady state on running. Int. J. Sports Med. 30(9): 643-646. PMID: 19569005

Stanford, K.I., Lee, M.Y., Getchell, K.M., So, K., Hirshman, M.F., and Goodyear, L.J. 2015. Exercise before and during pregnancy prevents the deleterious effects of maternal high-fat feeding on metabolic health of male offspring. Diabetes 64(2): 427-433. PMID: 25204976

https://mc06.manuscriptcentral.com/apnm-pubs 
Tegtbur, U., Busse, M.W., and Braumann, K.M. 1993. Estimation of an individual equilibrium between lactate production and catabolism during exercise. Med. Sci. Sports Exerc. 25(5): 620-627. PMID: 8492691

Voltarelli, F.A., Gobatto, C.A., and de Mello, M.A. 2002. Determination of anaerobic threshold in rats using the lactate minimum test. Braz. J. Med. Biol. Res. 35(11): 1389-94. PMID: 12426640

Wisloff, U., Helgerud, J., Kemi, O.J., and Ellingsen, O. 2001. Intensity-controlled treadmill running in rats: VO2 max and cardiac hypertrophy. Am. J. Physiol. Heart Circ. Physiol. 280 (3): 1301-1310. PMID: 11179077

Yan, Z., Lira, V.A., and Greene, N.P. 2012. Exercise training-induced regulation of mitochondrial quality. Exerc. Sport Sci. Rev. 40(3): 159-164. PMID: 22732425

Zagatto, A.M., Padulo, J., Muller, P.T., Miyagi, W.E., Malta, E.S., and Papoti, M. 2014. Hyperlactemia induction modes affect the lactate minimum power and physiological responses in cycling. J. Strength Cond. Res. 28(10): 2927-2934. PMID: 24736777 
Table 1. Intensities and blood lactate concentration of evaluation protocols (LM and MLSS) expressed as mean \pm standard deviation. Intensity of LM $(\mathrm{LM}-\% \mathrm{bm})$ and respective blood lactate concentration $\left(\mathrm{LM}_{\mathrm{C}}-\mathrm{mmol}^{-\mathrm{L}^{-}}\right.$

${ }^{1}$ ), intensity of MLSS (MLSS - \%bm) and respective blood lactate concentration $\left(\mathrm{MLSS}_{\mathrm{C}}-\mathrm{mmol}^{-1} \mathrm{~L}^{-1}\right.$ ), effect size (ES - d-Cohen's)

\begin{tabular}{|c|c|c|c|c|c|c|}
\hline Groups & $\begin{array}{c}\text { LM } \\
(\% \text { obm) }\end{array}$ & $\begin{array}{l}\text { MLSS } \\
(\% \mathbf{b m})\end{array}$ & $\begin{array}{c}\text { ES } \\
(d \text {-Cohen's) }\end{array}$ & $\begin{array}{c}\mathbf{L M}_{\mathbf{C}} \\
\left(\mathrm{mmol}^{-1} \mathbf{L}^{-1}\right)\end{array}$ & $\underset{\left(\mathrm{mmol}^{-L^{-1}}\right)}{\text { MLSS }_{\mathrm{C}}}$ & $\begin{array}{c}\text { ES } \\
(d-C o h e n ' s)\end{array}$ \\
\hline All mice & $5.18 \pm 0.67^{*}$ & $6.34 \pm 1.02$ & 1.34 & $3.03 \pm 0.77^{*}$ & $3.49 \pm 0.86$ & 0.56 \\
\hline Male & $5.02 \pm 0.61^{*}$ & $5.86 \pm 0.85$ & 1.13 & $3.33 \pm 0.87$ & $3.74 \pm 1.09$ & 0.41 \\
\hline Female & $5.38 \pm 0.72^{*}$ & $6.88 \pm 0.96$ & 1.76 & $2.70 \pm 0.51^{*}$ & $3.22 \pm 0.39$ & 1.14 \\
\hline
\end{tabular}

* Significant difference of MLSS or $\operatorname{MLSS}_{\mathrm{C}}(P<0.05)$

Table 2. Body mass (g) values for each gender expressed as mean \pm standard deviation and Pearson's correlation analysis results among intensities of protocols (LM and MLSS - \%bm) versus body mass (g).

\begin{tabular}{cccc}
\hline Groups & Body mass $(\mathrm{g})$ & LM vs. Body mass & MLSS vs. Body mass \\
\hline Male & $40.23 \pm 1.95^{*}$ & $\mathrm{r}=-0.13(\mathrm{p}=0.71)$ & $\mathrm{r}=-0.11(\mathrm{p}=0.76)$ \\
Female & $31.90 \pm 2.08$ & $\mathrm{r}=0.12(\mathrm{p}=0.74)$ & $\mathrm{r}=-0.23(\mathrm{p}=0.54)$ \\
\hline
\end{tabular}

\footnotetext{
* Significant difference of female. All cases $P<0.05$.
} 
Figure 1. Example of determination of the intensity of LM of a mouse during incremental phase. Each point of the curve represents the relationship among blood lactate concentration (mmol.L $\left.{ }^{-1}\right)$ versus intensity $(\% \mathrm{bm})$ during the stages $(5 \mathrm{~min})$ of the incremental phase. In this case, the lactate kinetic (U-shaped) and coefficient of determination $\left(\mathrm{R}^{2}\right)$ attended to the criterions of success required. The intensity of LM represent the minimum point or derived zero of the curve and it was estimated using a second order polynomial fit. The arrows indicates the intensity of $\operatorname{LM}(5.06 \% \mathrm{bm})$ and its blood lactate concentration $\left(3.38 \mathrm{mmol} . \mathrm{L}^{-1}\right)$

Figure 2. Variability of the intensities (\% bm) of LM and MLSS. (a) Differences among intensities of LM and MLSS for males $(\mathrm{P}<0.05)$; (b) Differences among intensities of LM and MLSS for females $(\mathrm{P}<0.05)$; and $(\mathrm{c})$ Differences between genders $(\mathrm{P}<0.05)$. On each box plot, the central mark is the median $\left(50^{\text {th }}\right.$ percentile $)$, the edges of the box represent the quartiles $25^{\text {th }}$ and $75^{\text {th }}$ percentiles. The whiskers extend to the most extremes points (minimum and maximum).

Figure 3. Pearson's correlation analysis among intensities of LM ( $\% \mathrm{bm})$ and MLSS (\% bm) to A) all mice $(n=19)$, B) Male $(n=10)$ ad C) Female $(n=9)$. The relationship among intensities was represented by linear regression (line) \pm confidence interval $(95 \% \quad-$ dashed line $)$. All cases $P<0.05$.

Figure 4. Limits of agreement among intensities of MLSS and LM (A) for all mice and (B) for male, and (C) for female through the Bland and Altman (1999) analysis. 


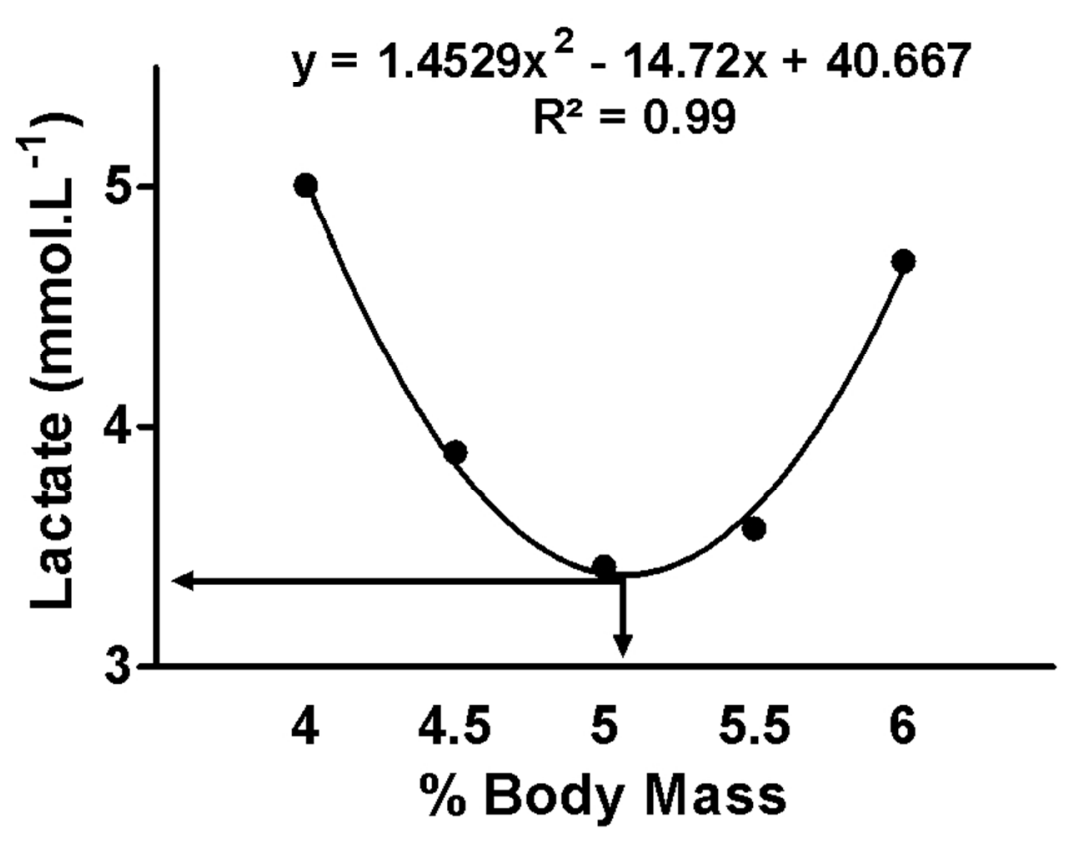

$85 \times 62 \mathrm{~mm}(300 \times 300$ DPI $)$ 


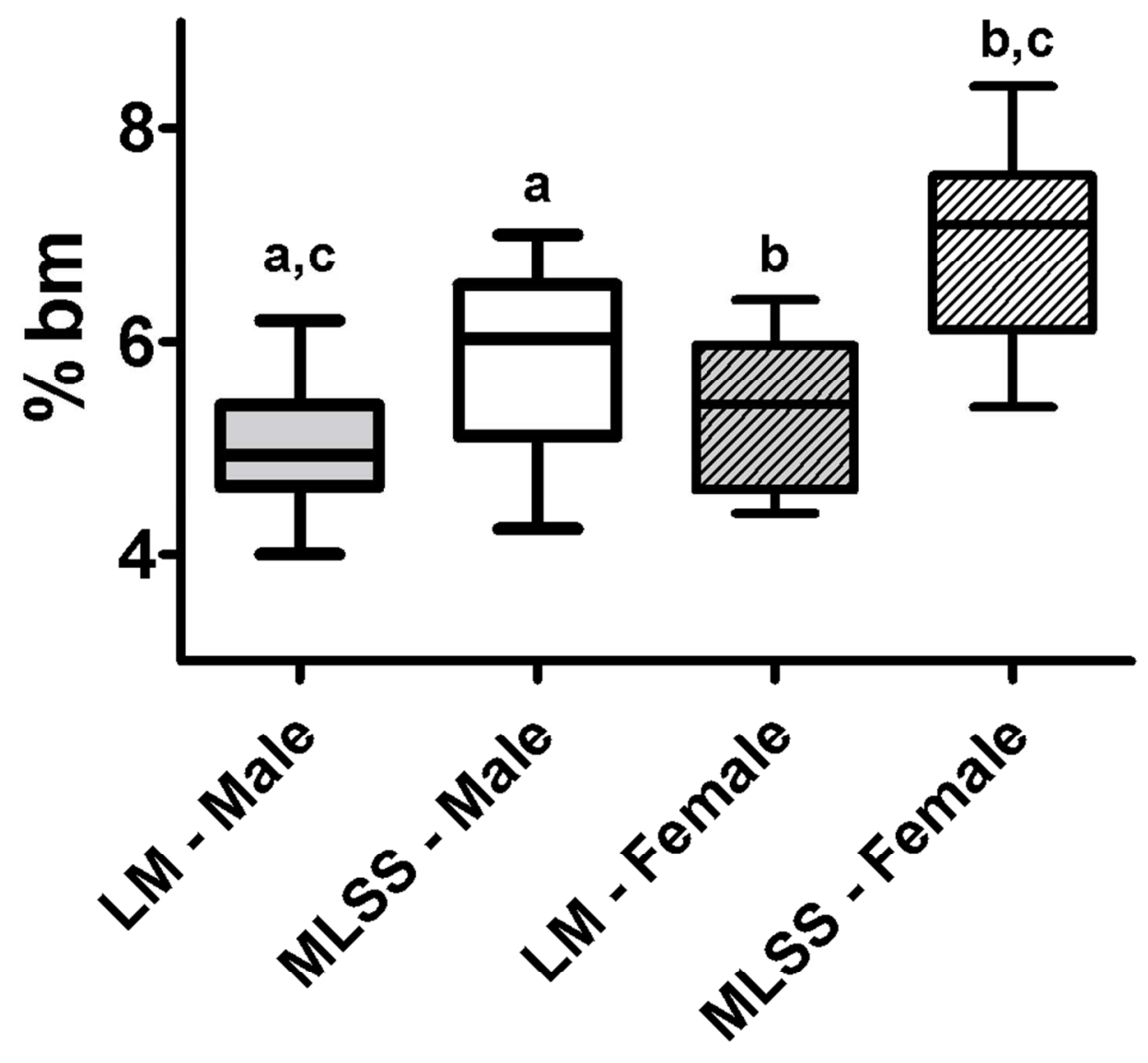

$85 \times 84 \mathrm{~mm}(300 \times 300$ DPI $)$ 

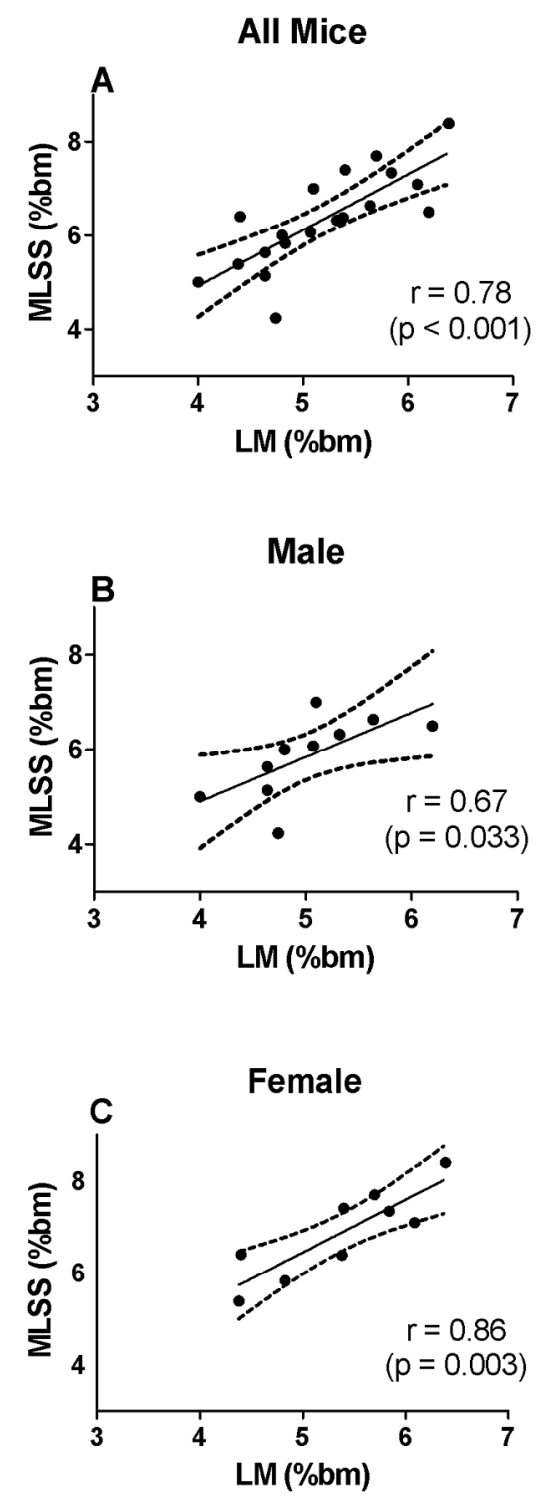

$85 \times 208 \mathrm{~mm}(300 \times 300 \mathrm{DPI})$ 

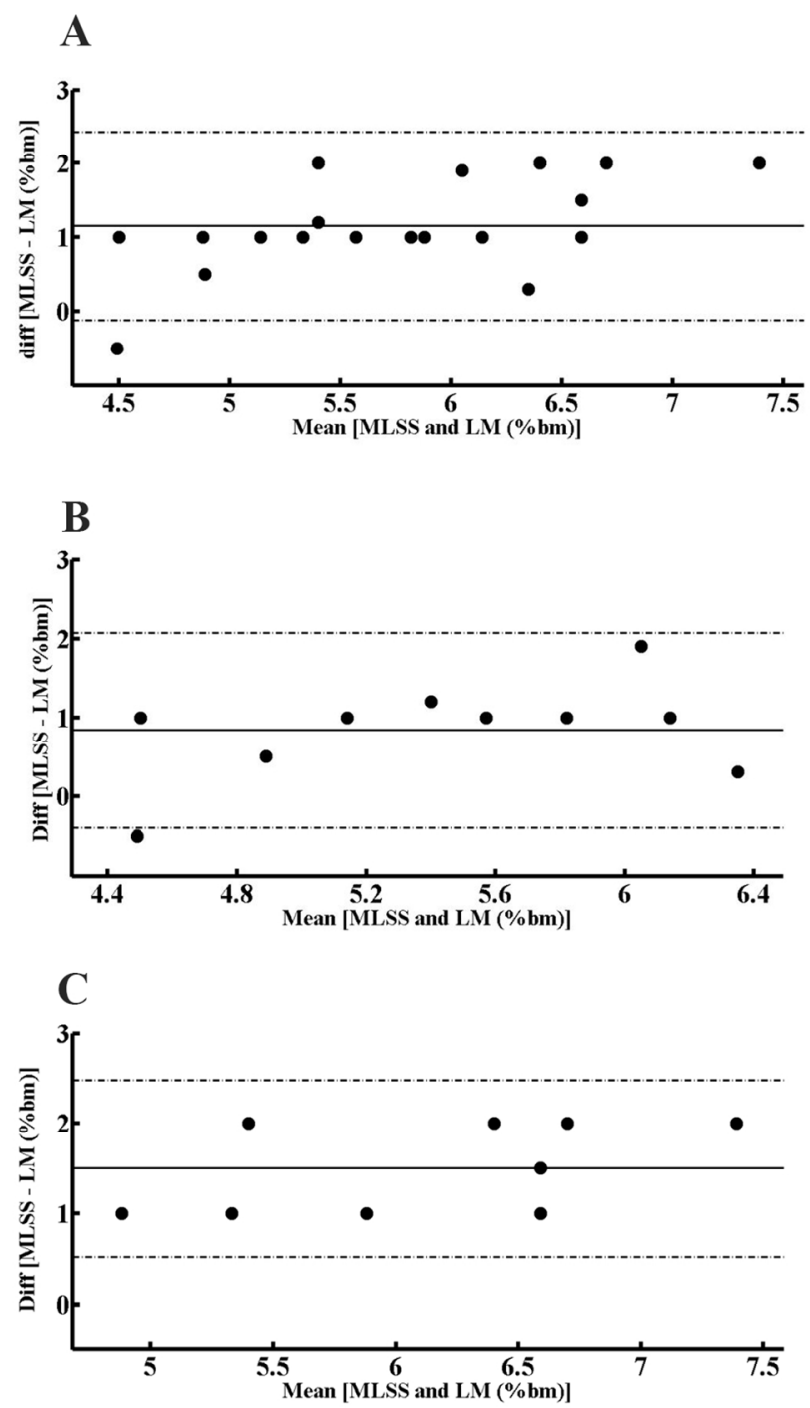

$86 \times 155 \mathrm{~mm}(300 \times 300 \mathrm{DPI})$ 